\title{
REPENSANDO O PROCESSO DE AVALIAÇÃO NOS \& DOS CURSOS DE GRADUAÇÃO EM ADMINISTRAÇÃO
}

\author{
Camila Olivieri IGARI ${ }^{1}$ \\ PUC/SP \\ camilaigari@uol.com.br \\ Adriana Backx Noronha VIANA ${ }^{2}$ \\ FEA/USP \\ backx@usp.br
}

Resumo: $O$ presente artigo apresenta, inicialmente, um panorama da avaliação oficial, ENADE/2012 (Exame Nacional de Desempenho de Estudantes), com destaque para cursos de graduação em Administração, que representam um contingente de $16,7 \%$ das matriculas em formações presenciais e 30,22\% das formações à distância nas diferentes áreas instrumentais excluindo os cursos de tecnólogos. Considerando as distâncias nos indicadores de qualidade das formações oferecidas, nos quais apenas $6 \%$ das graduações foram avaliadas com o Conceito 5 e grande maioria (43\%) recebeu o Conceito 3 , faz-se, assim, necessárias pesquisas acadêmicas que permitam identificar a relação dos impactos de avaliações institucionais e oficiais para a melhoria do ensino na área. Sugere-se, ainda, a elaboração de uma metodologia de avaliação de cursos num modelo de Framework de Avaliação de Ações Formativas que estabelece um diálogo entre a Avaliação responsiva de Stake (1978, apud. LUDKE,1983) e Metodologia de Avaliação de ações formativas para docentes em quatro níveis proposta Imbernon (2011) como uma adaptação do modelo de avaliação para formação em organizações de
Kirkpatrick e Kirkpatrick (2007), definindo-se, assim, um framework delineado pelos níveis: Diagnóstico (Prológo), Reações, Aprendizagens, Transferência e Abrangência. Para cada um dos níveis propostos há uma adaptação de instrumentos de coleta de dados e avaliadores conforme as especificidades de cada instituição formadora. A finalidade da aplicação do framework é oferecer um diagnostico do graduação em Administração considerando um plano de melhorias para a formação de administradores, unificado pelo diálogo e análise conjunta de conteúdos, das aprendizagens, das aplicações e os impactos para a atuação dos futuros administradores na percepção de formadores e formandos ou egressos num processo de avaliação sistêmico e customizado.

Palavras-chave: Ensino em Administração. Avaliação dos cursos de graduação em Administração. Avaliação sistêmica de ação formativa. Qualidade do ensino em Administração.

\footnotetext{
${ }^{1}$ Doutora em Educação: Psicologia da Educação pela PUCSP.

${ }^{2}$.Professora Associada da FEA/USP. Pós-Doutorado em Educação pela Universidade de Lisboa, Instituto de Educação. E-mail: backx@usp.br.
} 
Abstract: This article initially presents an overview of the official evaluation, ENADE / 2012 (National Examination of Student Performance), highlighting the graduation in business Administration, representing a quota of $16.7 \%$ of enrollment in classroom training and $30.22 \%$ of e-learning in differents instrumental areas excluding technologists courses. Considering the distances in quality indicators of training offered, in which only $6 \%$ of the graduation in business administration were evaluated with the Concept 5 and most $(43 \%)$ received the Concept 3 , it is necessary academics researches to identify the relationship the impact of institutional and official assessments for the improvement of education in the area. It is suggested the development of an assessment methodology in Formative Actions Assessment Framework model that establishes a dialogue between the Responsive Evaluation Stake (1978, apud. LUDKE, 1983) and Training Activities Evaluation Methodology for Teachers at four levels proposed Imbernon (2011) as an adaptation of the Evaluation Model for Training in Kirkpatrick and Kirkpatrick (2007), defining a framework outlined by levels: Diagnosis (prologue), Learning, Transfer and Coverage. For each proposed level adaptation was carried of the data collection instruments and evaluators according to the specificities of each educational institution. The purpose of the application of the framework is to provide a management in graduation diagnosis considering an improvement plan for the training of administrators, unified by dialogue and joint analysis of content of learning, applications and impact on the performance nagers in the perception of instructors and trainees and graduates in a systemic and customized evaluation process.

Keywords: Education in business administration. Training Activities Evaluation Methodology. Systemic evaluation of formative action. Quality of education in business administration. 


\section{Introdução}

O ensino de Administração no Brasil teve seu início na década de 1940, com a criação da Escola Superior de Administração de Negócios (ESAN/SP) e da Faculdade de Economia, Administração e Contabilidade da Universidade de São Paulo (FEA/USP), marcados pelo ensino de teoria administrativa até então ministradas em cursos de Ciências Econômicas e Ciências Contábeis (ALVARÃES e LEITE, 2009).

A Fundação Getúlio Vargas de São Paulo (FGV-SP) foi criada em 1944, originada no Departamento de Administração do Setor Público (DASP), com a finalidade de preparar profissionais especializados para a Administração Pública e Privada. (NICOLINI, 2003). O Departamento de Administração da FEA/USP em 1963, institui os cursos de Administração de Empresas e de Administração Pública (CONSELHO FEDERAL DE ADMINISTRAÇÃO, www.cfa.org.br).

Segundo Vieira (2014), as mudanças econômicas contribuíram para a profissionalização do Administrador: pela regulamentação da profissão na Lei $n^{\circ} 4.769$, de 9 de setembro de 1965. O artigo $3^{\circ}$ delineou que o exercício da profissão de técnico em Administração é privativo aos bacharéis em Administração Pública ou de Empresas (CONSELHO FEDERAL DE ADMINISTRAÇÃO, www.cfa.org.br).

Observou-se uma rápida expansão do ensino superior em Administração nas décadas de 1960 e 1970, com retomada deste processo no final de década de 1990 (CANOPF; FESTINALLI; ICHIKAWA, 2005). A Tabela 1 a seguir mostra a evolução dos cursos presenciais na área de Gerenciamento e Administração no Brasil no período de 1970 a 2010.

Tabela 1 - Evolução dos cursos presenciais na área de Gerenciamento e Administração no Brasil

$\begin{array}{cccc}\text { Ano } & \text { Cursos } & \text { Matriculados } & \text { Concluintes } \\ 1970 & 164 & 66.289 & 5.276 \\ 1980 & 247 & 134.742 & 21.746 \\ 1990 & 320 & 174.330 & 22.394 \\ 2000 & 821 & 338.789 & 35.658 \\ 2001 & 1.205 & 404.122 & 39.147 \\ 2002 & 1.413 & 493.104 & 54.656 \\ 2003 & 1.710 & 576.305 & 64.792 \\ 2004 & 2.046 & 640.724 & 88.322 \\ 2005 & 2.484 & 704.822 & 108.793 \\ 2006 & 2.836 & 768.693 & 122.227\end{array}$




$\begin{array}{llll}2007 & 2.886 & 798.755 & 120.562 \\ 2008 & 3.207 & 863.718 & 139.989 \\ 2009 & 3.958 & 870.536 & 155.364 \\ 2010 & 3.855 & 910.956 & 161.253\end{array}$

Fonte: MEC/INEP

Pode-se observar uma forte expansão da formação profissional em nível superior da área de negócios no Brasil nos anos 1990. Conforme Plutarco e Gradvohl (2010), tal expansão foi marcada pela oferta dos cursos de graduação em instituições privadas. Dados do Censo da Educação Superior (INEP/MEC/2010), os cursos da área de Gerenciamento e Administração ${ }^{3}$ apresentaram 910.956 alunos matriculados, correspondendo a 16,7\% do total de matrículas nos cursos presenciais do ensino superior no Brasil (VIEIRA, 2014).

Observou-se também o crescimento da quantidade de cursos a distância. O Censo da Educação Superior (INEP/MEC/2010) sinalizou que os cursos na área de Gerenciamento e Administração representavam 30,22\% das 930.179 matrículas no ensino à distância, conforme Censo (2010). Com mais de um milhão de estudantes, a área de Administração lidera o ranking dos cursos com maior número de alunos matriculados no Brasil (VIEIRA, 2014).

Tabela 2 - Dados sobre os cursos à distância na área de Gerenciamento e Administração no Brasil $2009 / 2010$

$\begin{array}{cccc}\text { Ano } & \text { Cursos } & \text { Matriculados } & \text { Concluintes } \\ 2009 & 186 & 228.321 & 28.018 \\ 2010 & 217 & 281.085 & 39.926\end{array}$

Fonte: Vieira (2014)

De acordo com Canopf; Festinalli e Ichikawa (2005), a expansão se deu pela não exigência de grandes investimentos em laboratórios, materiais e até mesmo grandes esforços para a composição do corpo docente. Saraiva (2011, p. 42) aponta que

\footnotetext{
${ }^{3}$ No Censo da Educação Superior do INEP/MEC, a área de Gerenciamento e Administração, engloba tanto os cursos de bacharelado em Administração quanto os cursos de tecnologia de áreas específicas da Administração, como por exemplo, Gestão de Recursos Humanos, Gestão Financeira etc. 
[...] o crescimento exponencial de cursos de Administração transformou esta área na locomotiva da educação superior brasileira, não apenas pelo glamour dos homens e mulheres de negócio, mas também pelas prováveis altas taxas de retorno associadas aos seus baixos custos operacionais.

Conforme Giroletti (2005), um dos grandes desafios do ensino superior de Administração está relacionado à transformação da expansão quantitativa em expansão qualitativa.

Salm, Menegasso e Moraes (2007, p. 2) discutem que

[...] os cursos superiores de administração proliferaram no Brasil a ponto de se encontrar em qualquer cidade uma faculdade ou um curso que forma administradores. Uma das maiores lacunas desses cursos é a falta de preparo dos professores para a prática docente.

Muitas vezes a prática docente não bem sucedida reflete no desempenho dos alunos. No dia 06 de dezembro de 2013 a seguinte notícia foi apresentada em jornal ${ }^{4}$ :

Em todo o país, 270 cursos de graduação não poderão realizar vestibulares para o ano que vem, por terem ficado com conceitos insatisfatórios na avaliação do Ministério da Educação (MEC) duas vezes consecutivas. No total, 44.069 vagas deixarão de ser ofertadas em 2014 no ensino superior.

[...] O maior número de cursos que serão punidos são de administração, 103. Em seguida, vem ciências contábeis (51), direito (38) e comunicação social (16). Foram avaliados ainda os cursos de ciências econômicas, design, psicologia, relações internacionais, secretariado executivo e turismo. Os cursos superiores de tecnologia das áreas de gestão comercial, gestão de recursos humanos, gestão financeira, logística, marketing e processos gerenciais também foram avaliados. Entre esses, 62 sofrerão as penalidades.

No ENADE 2012 (Exame Nacional de Desempenho de Estudantes) foram analisados 1554 cursos de Administração de um total de 6306 cursos de Humanas. Lembrando que a graduação em Administração corresponde a 25\% dos cursos da área ligada às humanidades. Com base no ENADE (2012), pode-se observar, que os cursos de Administração, comparativamente em percentual com os demais cursos de Humanas no Brasil apresentaram maior quantidade avaliações com notas 1 e 2 . Evidenciando que, apesar da expansão, a qualidade de fato ainda é um grande desafio considerando-se a necessidade de estudos focados na qualidade do ensino na área.

Tabela 3 - Distribuição do número de cursos por conceitos

\footnotetext{
${ }^{4}$ http://www.portugaldigital.com.br/sociedade/ver/20081869-ensino-superior-no-brasil-perdera-44-milvagas-em-2014 


\begin{tabular}{ccc} 
Conceito & $\begin{array}{c}\text { Todos os Cursos } \\
\text { (Brasil) }\end{array}$ & $\begin{array}{c}\text { Cursos de Administração } \\
\text { (Brasil) }\end{array}$ \\
5 & $5 \%$ & $6 \%$ \\
4 & $19 \%$ & $14 \%$ \\
3 & $44 \%$ & $43 \%$ \\
2 & $27 \%$ & $34 \%$ \\
1 & $3 \%$ & $2 \%$ \\
Sem Conceito & $2 \%$ & $1 \%$ \\
TOTAL & 6306 & 1554 \\
\hline
\end{tabular}

Fonte : ENADE, 2012

É importante ressaltar que não se pode avaliar a qualidade de um curso somente pelo conceito do ENADE, mas ele pode ser considerado como um indicador de comparação, tal como apresentado na Figura 1.

Figura 1 - Gráfico de Barras comparando a \% de cursos com notas 2 e 1 no Brasil na área de Humanas como um todo, em relação aos cursos de Administração

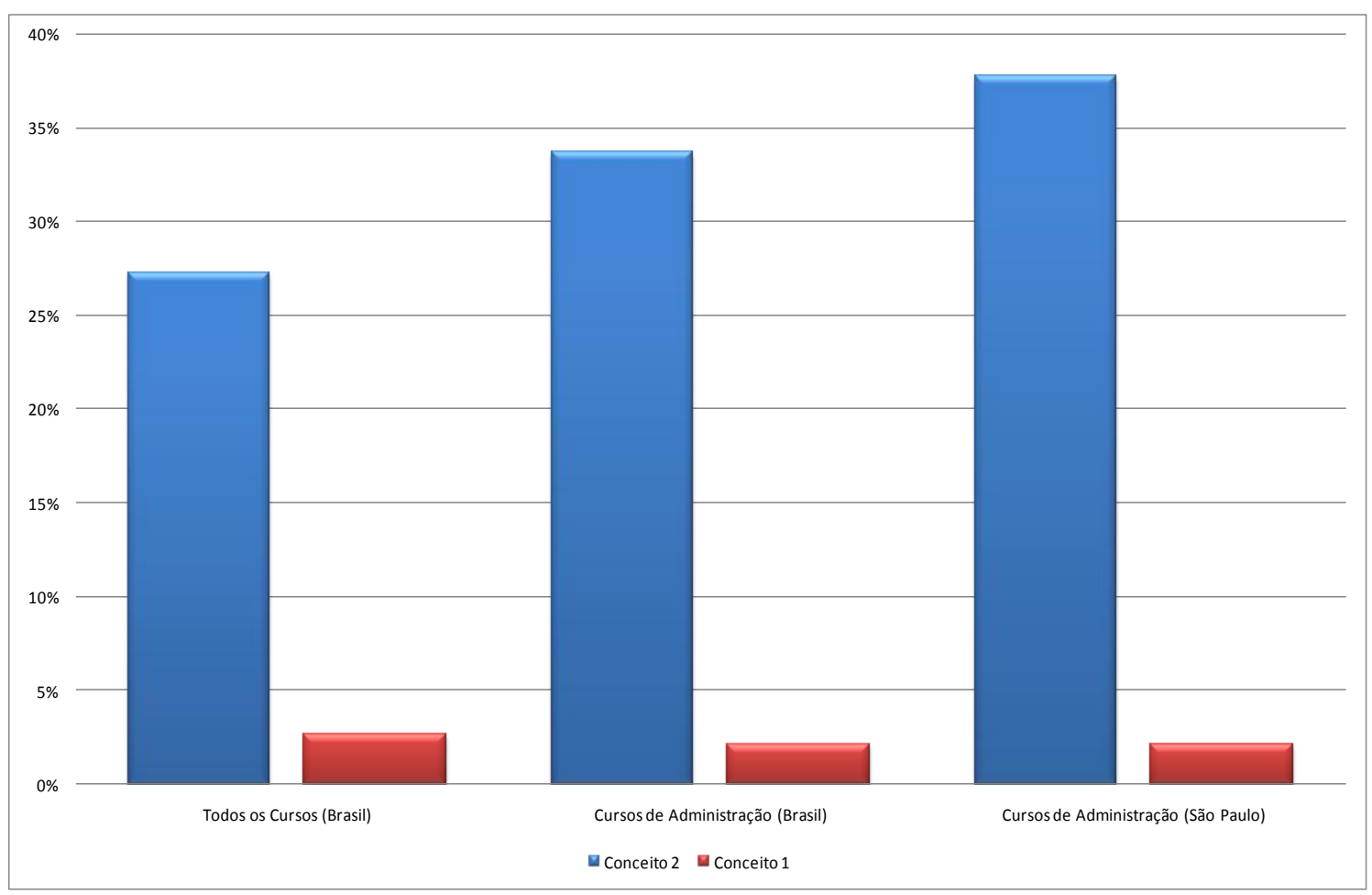

Fonte de dados: ENADE 2012

Os cursos de Administração com conceito 3 (ENADE/2012) tiveram média de acerto de $33 \%$ das questões, como destaca a especialista em Educação da Universidade de São Paulo, Paula Lozano em entrevista ${ }^{5}$. O conceito 5 no ENADE para o curso de

\footnotetext{
${ }^{5}$ http://g1.globo.com/educacao/noticia/2013/10/enade-nao-diz-se-curso-e-bom-so-se-e-melhor-ou-piorque-outro-entenda.html MARGENS - Revista Interdisciplinar

Dossiê: Formação Docente Versão Digital - ISSN: 1982-5374 
Administração corresponde a $45 \%$ de acerto. Segundo a especialista: todo mundo vai mal, é um curso de desempenho baixo. Emergem questões: Que fatores estão relacionados com esse desempenho baixo? Quais são os critérios de avaliação? Como podemos avaliar pensar pensando em melhorias para o ensino e aprendizado?

Fernandes (2013, p. 19) argumenta que ao avaliar deve-se olhar para as potencialidades e os limites em descrever as percepções dos formandos e dos próprios formadores a respeito da qualidade para o fenômeno avaliado e a qualidade do que se avalia. Para o autor, (FERNANDES, 2013, p. 22) qualidade é um conceito complexo e multifacetado cuja natureza torna muito difícil, ou mesmo impossível, a sua integral representação.

O que implica no avaliar um conjunto de decisões sobre objetivos e prioridades avaliativas, alicerçado na cooperação, compartilhamento de canais para informação e recursos disponíveis, bem como no uso de instrumentos adequados às especificidades das ações formativas (FERNANDES, 2013, p.14). Em um exercício de triangulação entre compreender a finalidade da formação, a expectativa dos formandos e a efetividade da ação formativa para o desenvolvimento de competências docentes.

Segundo Vianna (1989, p. 41) a finalidade de avaliar é gerar conhecimentos e decisões para a melhoria de determinada ação formativa, afastando-se do julgamento para a construção. Na busca por um olhar especifico que promova mudanças, os recursos devem ser múltiplos e complexos (interligados). Nessa perspectiva foi elaborado o framework de ação formativa como uma metodologia de avaliação formal que, segundo Fernandes (2013, p.16) deve refletir e integrar uma diversidade de aspetos informais e intuitivos para que se torne um instrumento efetivo não apenas para melhorias de futuras avaliações como também para mensurar o impacto para aprendizagem docente e de seus alunos ao longo do processo.

Em um levantamento de teses e dissertações desenvolvidas no Brasil sobre a área de ensino em administração, não se identificou trabalhos que trouxessem proposta no sentido de ampliar ou desenvolver contextos e aspectos relacionados à avaliação de cursos de graduação em administração. O quadro a seguir apresenta uma visão geral dos trabalhos identificados.

Quadro 1. Dissertações e teses sobre ensino em Administração 


\begin{tabular}{|c|c|c|c|}
\hline Título & Ano & Instituição & $\begin{array}{l}\text { Nome do Programa de } \\
\text { Pós-graduação }\end{array}$ \\
\hline $\begin{array}{l}\text { Desenvolvimento e Aplicação de um Modelo } \\
\text { Construtivista para o Ensino de Administração }\end{array}$ & 2011 & $\begin{array}{l}\text { Universidade } \\
\text { Federal do Rio } \\
\text { Grande do Sul } \\
\end{array}$ & $\begin{array}{l}\text { Programa de Pós- } \\
\text { Graduação em } \\
\text { Administração }\end{array}$ \\
\hline $\begin{array}{l}\text { Modelo relacional entre conhecimentos } \\
\text { transmitidos por cursos de especialização lato } \\
\text { sensu em Administração e seus impactos na } \\
\text { vida profissional: uma análise na perspectiva } \\
\text { dos alunos egressos }\end{array}$ & 2011 & $\begin{array}{l}\text { Universidade } \\
\text { Federal de Minas } \\
\text { Gerais }\end{array}$ & $\begin{array}{l}\text { Centro de Pós- } \\
\text { Graduação e Pesquisas } \\
\text { em Administração }\end{array}$ \\
\hline $\begin{array}{l}\text { Complexidade e Fragmentação na Dinâmica } \\
\text { Curricular de um Curso de Bacharelado em } \\
\text { Administração }\end{array}$ & 2012 & $\begin{array}{l}\text { Universidade } \\
\text { Católica de Brasília }\end{array}$ & $\begin{array}{l}\text { Programa de Pós- } \\
\text { Graduação } \\
\text { "StrictoSensu" em } \\
\text { Educação }\end{array}$ \\
\hline $\begin{array}{l}\text { O Papel do Mestrado Acadêmico em } \\
\text { Administração da PUC/Minas na Formação da } \\
\text { Competência Didático-Pedagógica do Egresso- } \\
\text { Professor }\end{array}$ & 2011 & PUC/MG & $\begin{array}{l}\text { Programa de Pós- } \\
\text { Graduação em } \\
\text { Administração }\end{array}$ \\
\hline $\begin{array}{l}\text { Estratégias de ensino balizadas pela } \\
\text { aprendizagem em ação: um estudo no curso de } \\
\text { graduação em administração da universidade } \\
\text { federal da Paraíba }\end{array}$ & 2011 & $\begin{array}{l}\text { Universidade } \\
\text { Federal da Paraíba }\end{array}$ & $\begin{array}{l}\text { Programa de Pós- } \\
\text { Graduação em } \\
\text { Administração }\end{array}$ \\
\hline $\begin{array}{l}\text { Análise do exercício da liderança na } \\
\text { Coordenação do Curso de Administração: } \\
\text { estudo de caso de uma IES do interior do } \\
\text { Estado de São Paulo }\end{array}$ & 2011 & $\begin{array}{l}\text { Universidade } \\
\text { Metodista de } \\
\text { Piracicaba }\end{array}$ & $\begin{array}{l}\text { Mestrado Profissional } \\
\text { em Administração }\end{array}$ \\
\hline $\begin{array}{l}\text { Currículo Projetado e o Currículo Vivido no } \\
\text { Curso de Graduação em Administração da } \\
\text { Pontifícia Universidade Católica de São Paulo: } \\
\text { O Projeto Pedagógico e o Ensino e } \\
\text { Aprendizagem da Pesquisa sob a Ótica dos } \\
\text { Professores }\end{array}$ & 2011 & PUC/SP & $\begin{array}{l}\text { Doutorado em } \\
\text { Educação: Currículo }\end{array}$ \\
\hline $\begin{array}{l}\text { Criação de simulador de gestão da produção } \\
\text { como tecnologia de ensino-aprendizagem }\end{array}$ & 2012 & $\begin{array}{l}\text { Universidade } \\
\text { Federal de Santa } \\
\text { Catarina } \\
\end{array}$ & $\begin{array}{l}\text { Programa de Pós- } \\
\text { Graduação em } \\
\text { Administração } \\
\end{array}$ \\
\hline $\begin{array}{l}\text { Formação, Atuação Profissional e Mercado de } \\
\text { Trabalho em Administração: O Caso dos } \\
\text { Egressos do Curso de Graduação da UFSM }\end{array}$ & 2011 & $\begin{array}{l}\text { Universidade } \\
\text { Federal de Santa } \\
\text { Maria }\end{array}$ & $\begin{array}{l}\text { Programa de Pós- } \\
\text { Graduação em } \\
\text { Administração, Área de } \\
\text { Sistemas, Estruturas e } \\
\text { Pessoas } \\
\end{array}$ \\
\hline $\begin{array}{l}\text { A relação de E-mentoring entre Professores } \\
\text { (Titular e Tutor) e Alunos na Educação a } \\
\text { Distância: um Estudo de Caso no Curso de } \\
\text { Graduação em Administração da UEPB } \\
\end{array}$ & 2011 & $\begin{array}{l}\text { Universidade } \\
\text { Federal de } \\
\text { Pernambuco }\end{array}$ & $\begin{array}{l}\text { Programa de Pós- } \\
\text { Graduação em } \\
\text { Administração }\end{array}$ \\
\hline $\begin{array}{l}\text { O sentido do estudo para os alunos de } \\
\text { graduação em administração e as percepções } \\
\text { dos agentes envolvidos nesse processo }\end{array}$ & 2012 & $\begin{array}{l}\text { Escola Brasileira de } \\
\text { Administração } \\
\text { Pública e de } \\
\text { Empresas } \\
\end{array}$ & $\begin{array}{l}\text { Doutorado em } \\
\text { Administração }\end{array}$ \\
\hline $\begin{array}{l}\text { Poder, Saber e Subjetividades: Constituição e } \\
\text { Formação dos Sujeitos ADM }\end{array}$ & 2011 & $\begin{array}{l}\text { Universidade } \\
\text { Federal do Espírito } \\
\text { Santo } \\
\end{array}$ & $\begin{array}{l}\text { Pós-Graduação em } \\
\text { Educação }\end{array}$ \\
\hline $\begin{array}{l}\text { Integrando a Sustentabilidade na Formação de } \\
\text { Administradores }\end{array}$ & 2011 & $\mathrm{PUC} / \mathrm{SP}$ & $\begin{array}{l}\text { Pós-Graduação em } \\
\text { Administração }\end{array}$ \\
\hline $\begin{array}{l}\text { Análise da Importância e Efetividade na } \\
\text { Utilização da Ferramenta Estudo de Caso para } \\
\text { Ensino em Disciplinas do Curso de } \\
\text { Administração de Empresas }\end{array}$ & 2011 & \begin{tabular}{|l|} 
Centro \\
Universitário \\
Franciscano do \\
Paraná
\end{tabular} & $\begin{array}{l}\text { Pós-Graduação em } \\
\text { Organizações e } \\
\text { Desenvolvimento }\end{array}$ \\
\hline
\end{tabular}




\begin{tabular}{|c|c|c|c|}
\hline Título & Ano & Instituição & $\begin{array}{l}\text { Nome do Programa de } \\
\text { Pós-graduação }\end{array}$ \\
\hline $\begin{array}{l}\text { Desafios do TCC Orientado na Modalidade a } \\
\text { Distância: Casos do Curso de Graduação em } \\
\text { Administração e Especialização em } \\
\text { Negociação Coletiva da Escola de } \\
\text { Administração da UFRGS }\end{array}$ & 2012 & $\begin{array}{l}\text { Universidade } \\
\text { Federal do Rio } \\
\text { Grande do Sul }\end{array}$ & $\begin{array}{l}\text { Programa de Pós- } \\
\text { Graduação em } \\
\text { Administração }\end{array}$ \\
\hline $\begin{array}{l}\text { Atitude e Motivação em Relação ao } \\
\text { Desempenho Acadêmico de Alunos do Curso } \\
\text { de Graduação em Administração em } \\
\text { Disciplinas de Estatística }\end{array}$ & 2012 & $\begin{array}{l}\text { Faculdade de } \\
\text { Economia, } \\
\text { Administração e } \\
\text { Contabilidade de } \\
\text { Ribeirão Preto }\end{array}$ & $\begin{array}{l}\text { Programa de Pós- } \\
\text { Graduação em } \\
\text { Administração de } \\
\text { Organizações }\end{array}$ \\
\hline
\end{tabular}

Fontes: Igari e Backx (2015).

Em geral, os trabalhos levantados discutem sobre formação, práticas didáticas e questões curriculares. Observou-se assim, uma possível lacuna no que se refere ao processo de avaliação do curso, durante o desenvolvimento do curso e os impactos da formação profissional. Observou-se, ainda, a importância de desvelar os caminhos percorridos pelos egressos como abrangência da formação como indicador também de avaliação de qualidade dos aprendizados. Assim, delineia-se o objetivo do artigo de promover uma reflexão da possibilidade de implementar o framework de avaliação de avaliação formativa objetivando-se ao mensurar os impactos da formação na atuação do administrador contribuir para melhorias dos cursos de graduação em Administração.

Considerando que o framework proposto tem como norteador os descritores de avaliação definidos por Fernandes (2013, p. 30):

1. Não é uma ciência exata nem uma mera técnica;

2. Não se reduz a uma medida, sendo uma prática social sofisticada que exige participação e interação social;

3. Não produz, em geral, resultados exatos nem definitivos; porém, deverá ser credível, rigorosa e útil para todos os intervenientes no processo;

4. Permite discernir a qualidade de qualquer objeto, sendo muitas vezes desejável que esse discernimento seja feito com base na utilização complementar de avaliações baseadas em critérios e de avaliações baseadas na experiência e nas práticas das pessoas; e

5. Deve ser utilizada para melhorar a vida das pessoas, das organizações e das sociedades, sem que dela se deixem de retirar as devidas consequências que, normalmente, implicam a regulação e a autor regulação do ente avaliado. 
Nasce o desafio de elaborar um Framewok de Avaliação de Ação Formativa o qual promova um olhar sistêmico para a formação mensurando seus impactos em uma abordagem descritiva de avaliação das ações formativas aplicada por Stake (desde o final dos anos 1960) em diálogo com a metodologia de avaliação em quatro níveis (sistêmica) como propõe Imbernon (2011), com base em Kirkpatrick e Kirkpatrick (2007).

\section{Bases para elaboração do framework: Stake, Kirkpatrick e Imbernon}

Stake (1978, apud. LUDKE, 1983, p.16), numa perspectiva sociológica, convida os formandos a mensurar os efeitos da formação por meio de uma avaliação responsiva pluralista, analisando impactos das aprendizagens para a mudança em sua pratica. Ou seja, a palavra é dada ao sujeito e sua subjetividade em observações e entrevistas, bem como torna possível a avaliação sob olhar de outros agentes que sofrerão os impactos (benefícios) da ação formativa. Converge para uma pesquisa qualitativa especifica para qual Vianna (2000, p. 39) apresenta um rol de procedimentos para realização de uma avaliação responsiva conforme Stake:

1. Discutir com os responsáveis pela formação: o escopo, as atividades do programa, os propósitos e preocupações;

2. Conceituar questões e problemas e necessidades de dados;

3. Selecionar observadores, juízes e até mesmo instrumentos, se necessários;

4. Observar antecedentes, interações e resultados, como no modelo countnance;

5. Preparar descrições, estudos de casos;

6. Validar - confirmar ou "desconfirmar";

7. Elaborar informações para vários públicos; e

8. Apresentar relatório formal, se for o caso.

$\mathrm{Na}$ perspectiva de uma avaliação responsiva é possível captar a dinâmica da formação desde a sua concepção até o impacto dos resultados, por meio de ajustes nos procedimentos de avaliação com a realidade. A ideia de captar a dinâmica implica também em um diálogo com o objeto. Todo o processo de julgamento ou valoração, assim, se dá em um movimento de análise das intenções, das contingências e das congruências. 
Na constituição do framerork propõe-se, assim, um nível anterior que contempla a avaliação responsiva como prólogo de avaliação, um nível nomeado de Diagnóstico marcado pelo diálogo com um modelo de avaliação normativa com a finalidade de assegurar seu rigor ou validação a partir de um olhar sistêmico e customizado sob a ação formativa.

Na elaboração do Framework de Avaliação de Ações Formativas os níveis estabelecidos por Imbernón (2011,p. 81) na Metodologia de Avaliação de Ações Formativas para docentes: reação, aprendizagens, conduta e resultado são definidos em Diagnóstico, Reações, Aprendizagens, Transferências e Abrangências.

Assim, no segundo nível de avaliação da Reação propõe-se avaliar a satisfação do formando em relação à ação formativa em si: a relevância dos conteúdos desenvolvidos para sua aprendizagem docente, a qualidade dos formadores, das aulas e dos materiais didáticos, o ambiente nas relações interpessoais com os formadores e pares, o apoio administrativo, as condições de tempo e espaço (ambiente para a aprendizagem). Ou seja, compreende uma avaliação do curso. Por focar na ação formativa propriamente dita, a avaliação da reação implica em melhorias objetivas na estrutura do curso para futuras aplicações. Kirkpatrick e Kirkpatrick (2007, p. 51) sugerem que é desejável apresentar um feedback para os formandos, compartilhando o plano de melhorias para a nova aplicação, ou seja, valorizar o feedback do formando é uma maneira de expressar que há uma compreensão das suas necessidades e desejos.

Aprendizagens, como terceiro nível na avaliação, estão relacionadas aos conhecimentos relativos a conceitos, procedimentos, atitudes, valores e normas como aquisições da ação formativa que iniciam um movimento de especialização das aprendizagens docentes pelo desenvolvimento de competências docentes. Segundo Kirkpatrick eKirkpatrick (2007, p. 69) para essa etapa de avaliação o foco é o movimento para mudança por meio dos conhecimentos adquiridos, das habilidades desenvolvidas e das atitudes; afinal aprendizagem compreende mudança. Para tornar mais eficiente a avaliação da aprendizagem Kirkpartrick e Kirkpatrick (2007) e Imbernón (2011) sugerem a eleição de um grupo controle (máximo 5 pessoas) a ser mantido para os demais níveis de avaliação com um olhar mais qualitativo.

A avaliação das Transferência compreende a aplicação das aprendizagens no desenvolvimento de competências. Kirkpatrick e Kirkpatrick (2007, p. 80) sugerem que 
a avaliação da conduta ou transferência, como propõe Imbernón (2011) deve ser realizada após o termino da ação formativa para identificar a integração das novas competências desenvolvidas. Para esse nível, outros participantes devem ser incorporados na avaliação, no caso especifico, os alunos dos docentes em formação, para que possam pontuar as mudanças que identificaram na atuação dos docentes a mudanças nos conhecimentos, habilidades e atitudes.

No último nível das Abrangências o objetivo é analisar o resultado ou o impacto da ação formativa para a melhoria do ensino ou formação na área por meio da integração das competências pessoais e profissionais adquiridas e especializadas aplicadas. Convoca a uma visão em longo prazo dos impactos da relação entre competências e aprendizagens. Implica em uma análise mais abrangente do antes e do depois da formação confrontando o desejo pela formação, a realidade da formação e a melhoria do processo de ensino e aprendizagem, na perspectiva da instituição universitária e da constituição de profissionalidade do administrador.

Abbad, Gama e Borges-Andrade (2000, p. 25) sustentam que a validação de escalas de avaliação de reações ao treinamento, bem como os resultados da análise do relacionamento entre os três mais tradicionais níveis: reação, aprendizagem e impacto do treinamento no trabalho. Entretanto, considerando o tamanho da população (egressos do graduação) e o objetivo em si de formar (processo de formação profissionais) sugere-se aplicar escalas de mensuração as quais permitam análise quantitativa e mesmo relacional entre os níveis analisados, tendo em vista um contexto mais qualitativo.

Remete ao nível de Diagnóstico como finalidade confrontar por meio do histórico do formando as expectativas e os desejos aos caminhos escolhidos. Acrescentando, assim, à metodologia proposta um olhar sobre a finalidade da formação e os passos para sua constituição. O Diagnóstico compreende, no diálogo com os coordenadores da formação, conforme Stake uma avaliação responsiva focada na ação formativa em seus aspectos objetivos: para que formar (finalidade ou as competências não desenvolvidas), com quem formar (escolha das parcerias para a ação), como formar (a escolha dos conteúdos e das metodologias de ensino), a contribuição para a área e os interesses dos formadores. É o momento no qual a coordenação do curso desenvolvido tem a oportunidade de apresentar seus interesses e suas expectativas também em relação ao processo de avaliação. 
Concomitante, deve-se assumir um diálogo com os formandos, conhecendo suas motivações e interesses em realizar a formação. É o momento de apresentar a metodologia de avaliação continua e mobilizá-los para o compromisso com o processo. Envolver os formandos para que eles se sintam também responsáveis pela construção da avaliação, para que a avaliação não seja reduzida a uma burocracia caminhando para a melhoria.

A finalidade de introduzir o novo nível é mapear caminhos já percorridos pensando em um planejamento do processo de avaliação que aproxime a avaliação da realidade de seu objeto - a ação formativa - por meio da escuta dos interesses, motivações e expectativas. O contato inicial avaliador com formadores e formandos anuncia do que será falado: uma avaliação sistêmica em longo prazo com o objetivo de mensurar seus impactos em determinada formação. O como será falado se dá no dialogo estabelecido entre os instrumentos de avaliação e o vínculo entre os avaliadores com os formadores e formandos.

\section{Reflexões e Proposta de Framework para avaliação de cursos em graduação em Administração}

Pensando na graduação em Administração como processo de profissionalização do administrador em 4 anos complementado por estágios, a tarefa de mensurar sua qualidade se torna uma missão ainda mais complexa. Comumente, as instituições utilizam instrumentos padrões de fácil preenchimento com respostas fechadas, em análise funcional com foco especifico em disciplinas individuais. Geralmente são instrumentos aplicáveis para diferentes cursos. O impacto das informações geradas tem foco em ações para mudanças e ajustes isolados para melhorias especificas.

A ideia de uma avaliação que promova uma visão panorâmica da graduação e seus impactos para atuação do administrador deve ter como ponto de partida uma mudança de postura dos formadores em relação a concepção e ao ato de avaliar, envolvendo-os num processo, como propõe Fernandes (2013, p. 14), de finalidade especifica que se define por um conjunto de decisões sobre objetivos e prioridades avaliativas, alicerçado na cooperação, compartilhamento de canais para informação e recursos disponíveis, bem como com uso de instrumentos adequados às especificidades das ações formativas. Nessa perspectiva o framework proposto considera tais aspectos, principalmente para avaliação no nível de Diagnostico apresentando a finalidade e a estrutura da formação sob olhar das competências a serem desenvolvidas e as demandas do mercado. Assim, faz-se necessário 
um compromisso de disponibilidade exigida aos formadores como determinante para sua implementação.

Ter um grupo de formadores dispostos a contribuir para a avaliação longitudinal é um desafio devido às condições do transito dos docentes por diferentes instituições, principalmente nos contextos nos quais não há uma cultura de pesquisa.

Por outro lado, o compromisso de avaliar tendo como juízes os formandos apresenta, também, dificuldades em relação ao compromisso de avaliar, considerando o problema de desistência (do curso de graduação) entre os graduandos.

Lembrando que no nível de Diagnostico converge num exercício inicial de triangulação entre compreender a finalidade da formação, a expectativa dos formandos e a efetividade da ação formativa para o desenvolvimento de competências e atuação dos formadores. Para esse nível de avaliação serão os juízes: coordenação, formadores, calouros e egressos da graduação. Entrevistas individuais e focusgroups são os instrumentos mais apropriados.

Enfatiza Vianna (1989, p. 41) que no exercício de avaliar é preciso criatividade e precisão com foco em gerar caminhos para construção de conhecimentos e decisões para a melhoria da formação. $\mathrm{Na}$ busca por um olhar específico, os caminhos para medir a efetividade se tornam múltiplos e complexos conforme a magnitude da ação formativa, no caso, uma profissionalização que inclui o desenvolvimento de conhecimentos da profissão, habilidades específicas do profissional e atitudes desejadas. Por tratar-se de uma profissionalização, o framework de ação formativa como uma metodologia de avaliação formal que, segundo Fernandes (2013, p.16) deve refletir e integrar uma diversidade de aspetos informais e intuitivos para que se torne um instrumento efetivo não apenas para melhorias de futuras avaliações como também para mensurar o impacto para aprendizagem da profissão. Pede-se aos avaliadores que tenham o rigor na coleta de informação atentos aos instrumentos, contudo, eles possam lançar mão de ferramentas adicionais conforme sua necessidade de aprofundamento de informações.

Os demais níveis de avaliação exigirão um delineamento específico dos objetivos mensurados nas aprendizagens e transferência para cada uma das disciplinas, alinhados as competências a serem desenvolvidas. Sugere-se, assim, um levantamento de rol de competências essenciais ao administrador possíveis de serem desenvolvidas ao longo da formação, especificando o momento ou disciplina que será responsável por seu 
desenvolvimento. Um rol de indicadores de desenvolvimento por disciplinas como um instrumento auto aplicável com foco na curva de desenvolvimento profissional.

As análises das transferências exigem um amadurecimento que a experiência do mundo do trabalho propicia, mesmo que nos estágios, implicandoa coleta de dados entre os formandos mais experientes dos anos finais de formação. São os avaliadores para melhorias futuras, uma avaliação nesse momento permite uma reflexão não apenas sobre defasagens com perspectiva de escolhas futuras. Muitos egressos expressam, imediatamente após a graduação dúvidas em relação ao caminho a seguir devido as múltiplas possibilidades que se abrem nas diferentes áreas funcionais da Administração. Talvez a avaliação contribua para escolhas mais segura.

Um avaliação que inclui a análise das aprendizagens e a aplicabilidade dos conhecimentos, habilidades e atitudes representa um avanço para futuras melhorias na formação com focos em seus aspectos subjetivos com pistas para reflexão sobre a grande inquietação comum entre os formandos: Agora, o que eu faço com o meu diploma?

Os aspectos objetivos tem sido foco das avaliações, até então, resultando em adequações de conteúdos, metodologias de ensino e aprendizagem ou posturas docentes. A nova proposta de uma metodologia de avaliação busca delinear as preocupações com melhorias nos indicadores objetivos mensuráveis no nível de Reação. Muitas vezes, as avaliações são restritas a essas mudanças possíveis que estão atreladas as responsabilidades das instituições.

Analisar as partes, ou seja, as disciplinas que compõe a grade seja por período ou por afinidade nas áreas funcionais da Administração para os níveis de Reação, Aprendizagens e Transferências permite uma investigação cadenciada com possibilidades de aprofundamento de informação pela recorrência nos encontros com os juízes.

A finalidade da aplicação do framework é oferecer um plano de melhorias para a formação de administradores pelo diálogo e análise conjunta de formadores e formandos. O nível de Abrangência ao ampliar o escopo pela avaliação dos impactos da formação para o administrador egresso em atuação no mercado será o ponto inicial para as mudanças efetivas como produto da avaliação. 


\section{Considerações Finais}

A avaliação ENADE mostra que o que ocorre na área de administração em termos de formação de estudantes apresenta caminhos tortuosos, ou seja, não está bem estruturada. Assim, pensar em um processo mais integrativo, que permita um olhar dinâmico dessa formação e identificar pontos fracos, podem contribuir para melhorias no processo de formação em administração.

No presente artigo, objetivou-se apresentar um Framework de Avaliação de Ações Formativas que estabelece um diálogo entre a Avaliação responsiva de Stake (1978, apud. LUDKE,1983) e Metodologia de Avaliação de ações formativas para docentes em quatro níveis proposta Imbernon (2011) como uma adaptação do modelo de avaliação para formação em organizações de Kirkpatrick e Kirkpatrick (2007), definindo-se, assim, um framework delineado pelos níveis: Diagnóstico (Prológo), Reações, Aprendizagens, Transferência e Abrangência. Tal framework possibilita um olhar sistêmico e contributivo, permitindo um repensar do processo de avaliação nos e dos cursos de graduação em Administração prol da melhoria da formação de futuros Administradores.

\section{REFERÊNCIAS}

ALVARÃES, A. C. T.; LEITE, L. S. Práticas pedagógicas no curso superior de administração: uma abordagem transdisciplinar e o processo ensino-aprendizagem sociotécnico. Cadernos da Escola de Negócios, Curitiba, n. 7, p. 1-20, 2009. Disponível em:

$<$ http://apps.unibrasil.com.br/revista/index.php/negociosonline/article/viewFile/294/229 >. Acesso em: 26 set. 2012.

CANOPF, L.; FESTINALLI, R. C.; ICHIKAWA, E. Y. A expansão do ensino superior em Administração no sudoeste do Paraná: reflexões introdutórias. Revista de Administração Contemporânea, Curitiba, v. 9, n. 3, p. 79-97, jul./set. 2005. Disponível em: $<$ http://www.scielo.br/scielo.php?pid=S1415-

65552005000300005\&script=sci_arttext $>$. Acesso em 22 set. 2012.

CAPES - Coordenação de Aperfeiçoamento de Pessoal de Nível Superior, Edital PróAdministração, 2008. Disponível em: http://www.capes.gov.br/bolsas/programasespeciais/pro-administracao

CONSELHO FEDERAL DE ADMINISTRAÇÃO. História da profissão. Brasília, [200-?]. Disponível em: <http://www2.cfa.org.br/administrador/diversos/pagina-teste1>. Acesso em: 29 set. 2012. 
FERNANDES, Domingos. Avaliação, Ensino e Aprendizagens No Ensino Superior em Portugal e no Brasil: Realidades e Perspectivas (2009). Disponível em: http://www.ie.ul.pt/portal/page?_pageid=406,1208815\&_dad=portal\&_schema=PORT AL

GIROLETTI, D. Administração no Brasil: potencialidades, problemas e perspectivas. Revista de Administração de Empresas, São Paulo, v. 45, edição especial, p. 116-120, 2005. Disponível em: <http://rae.fgv.br/sites/rae.fgv.br/files/artigos/10.1590_S003475902005000000010.pdf>. Acesso em: 22 set. 2012.

HUBERMAN, M. O ciclo de vida profissional dos professores. In: NÓVOA, A. (Org.). Vidas de professores. 2. ed. Porto: Porto, 2000. p.31-61.

IMBÉRNON, F. Escola, formação de professores e qualidade de ensino. Paraná: Editora Melo, 2011.

. Formação docente e profissional. São Paulo: Editora Cortez, 2010.

Formação permanente do professorado - novas tendências. São

Paulo: Editora Cortez, 2009.

KIRKPATRICK, Donald L. e KIRKPATRICK, J. D. Como avaliar programas de treinamento de equipes - Os quatro níveis. Rio de Janeiro: Editora Senac, 2010.

Evaluación de acciones formativas. Barcelona: Gestion, 2007.

LUDKE, H. Discussão do trabalho de Robert E. Stake: Estudo de Caso em pesquisa e avaliação educacional. São Paulo, Fundação Carlos Chagas, pp. 15-18, jan/jun, 1983.

NICOLINI, A. Qual será o futuro das fábricas de administradores? Revista de Administração de Empresas, São Paulo, v. 43, n. 2, p. 44-54, abr./jun. 2003. Disponível em: <http://rae.fgv.br/rae/vol43-num2-2003/qual-sera-futuro-fabricas-administradores>. Acesso em: 22 set. 2012.

PLUTARCO, F. F.; GRADVOHL, R. F. Competências dos professores de Administração: a visão dos alunos de cursos de graduação. In: ENCONTRO NACIONAL DA ANPAD, 34, 2010, Rio de Janeiro. Anais... Rio de Janeiro: ANPAD, 2010. p. 1-16.

SALM, J. F.; MENEGASSO, M. E. MORAES, M. C. B. A Capacitação Docente em Administração: Referenciais e Proposições. In: ENCONTRO DE ENSINO E PESQUISA EM ADMINISTRAÇÃO E CONTABILIDADE, 1, Recife. Anais... Recife: ANPAD, 2007. p. 1-10.

SARAIVA, L. A. S. A educação superior em Administração no Brasil e a questão da emancipação: um túnel no fim da luz? Revista Gestão e Planejamento, Salvador, v. 12, n. $1, \quad$ p. 41-60, jan./jun. 2011. Disponível em: <http://www.revistas.unifacs.br/index.php/rgb/article/view/1296>. Acesso em: 22 set. 2012. 
VIANNA, H. M. Avaliação de programas: duas questões. Estudos em Avaliação Educacional, São Paulo, n. 32. p. 43-56, 2005.

Avaliações nacionais em larga escala: análises e propostas. Estudos em Avaliação Educacional, São Paulo, n. 27. p. 41-76, 2003.

- Programas de Avaliação em Larga Escala: algumas considerações. Estudos em Avaliação Educacional, São Paulo, n. 23. p. 93-104, 2001.

IBRASA, 2000.

Avaliação Educacional: teoria, planejamento e modelos. São Paulo:

Avaliação Educacional: vivência e reflexões. Estudos em Avaliação Educacional, São Paulo, n. 18. p. 69-109, 1998.

Avaliação Educacional: uma perspectiva histórica. Estudos em Avaliação Educacional, São Paulo, n. 12. p. 7-24, jul./dez. 1995.

Introdução à Avaliação Educacional. São Paulo: IBRASA, 1989.

Testes em Educação. 3 ed. São Paulo: IBRASA, 1978.

VIEIRA, A. R. A formação de professores para o ensino de Administração baseado em competências: possibilidades e desafios. Tese de Doutorado, USP Ribeirão Preto, 2014. 